\title{
General Discussion to the Papers of Dr Singer, Dr Rezaian and Drs Brodner and Dohrmann
}

Dr Leon Proctor (U.S.A.). I would like to ask Dr Singer a question with respect to the first paper, which was on the cortical-evoked potentials. We tried to apply this study to the human situation in all cases of course and he is measuring the return of integrity of the spinal thalamic tracts by doing cortical-evoked potentials. The question in humans of course is whether this reflects in any way in the integrity of the cortical spinal tracts, the motor pathways.

DR SINGER. In the cat, the situation is somewhat different from what it appears to be in the human. First of all, there isn't a very good spinal thalamic tract per se. Moran showed that not only are afferent responses conducted in the dorsal columns but also in the lateral part of the spinal cord probably the dorsal spinal cerebellar tracts in cats, and the destruction of both of these was necessary to abolish cortical responses. So in the cats, since the lateral tract lies fairly close to the cortico-spinal tract, one can at least theoretically expect that the cortical spinal tract and afferent responses are probably reflected by the solely afferent responses. Other people, particularly Kraft, tried to measure pyramidal tracts-cortical spinal tract responses stimulating the cerebral peduncle and motor cortex and recording from sciatic nerve-and they found that there didn't appear to be any difference. In the human the situation is somewhat different. Gibbon has shown that cortical responses seem to correlate best with lost posterior column sensation, so there may be a difference between whether the afferent responses reflect motor integrity of the cord in cats and humans.

Dr Yeo (Australia). I should like to ask the speakers about turnover. It seems to me that one of the things that fascinated us that although we are making a static measurement of the levels of norepinephrine and suratanum and not finding a rise as has been reported, we wondered in fact if there is an increased or decreased turnover. I should like to address particularly to Dr Sahgal and the other members of the panel whether in fact they know of any turnover studies of norepinephrine which seems for instance to be important as to whether you are measuring at one time what really reflects a very much increased destruction of norapinephrine or increase, whichever it is.

DR D. Rowed (Canada). I would like to direct this one to Dr Singer as well, and I wonder if he found any correlation during the recovery phase of evoked potential between the time of recovery, time of return of evoked potential and the normality or abnormality of the wave form and the rate of clinical recovery.

DR SINGER. The one animal who did not recover had a long latency $40 \mathrm{ml}$ a second rather prolonged waves, which I'm not really sure of the significance of. I was thinking perhaps it was a product of non-specific reticular system or reticular tract or something like that. On the other hand Singer et al. showed that in the monkey they got recovery of cortical responses and no recovery of reticular formation responses, thinking that perhaps those are more responsive actually than the cortical responses, so I'm not sure of that. As far as the absolute correlation of when the animal recovers and when the response returns, in three of the animals it was within 3 to 6 days of the time that the animal first began walking. In one animal it was considerably before that. I think there is some difficulty in judging clinical recovery in cats for one thing, because it maybe somewhat difficult to motivate the animal to walk until he decides to get up and walk. If he has been paraplegic he may be able to walk but just may not do it. That's certainly a variable factor. The other thing is that I think a larger series is necessary as well as work on primates, probably to determine specifically if the range and the number of animals in which this recovery occurs.

DR SAHGAL. I think at this point, one of the reasons why chemical studies have given such variable results is essentially the phenomenon that you are talking about. However, on fluorescent chemical studies since it is membrane bound and, as we all know, physiologically speaking, that for every molecule of adrenaline or norepinephrine that is liberated you have a loss of ATP, so the number of animals histochemically does cover a 
lot because we are not going at moderate increase or mild increase or decrease, we go by whether it is present or not. If there is intense fluorescence as we see above the level of the lesion in which you see yellow fluorescence granual bound, as long as it stays membrane bound I feel strongly that it has very little effect on the parenchyma of the spinal cord, but the moment it is released, be it because of anoxia, be it because of platelet distribution, you know the serotonin is coming out of the platelets. Thus it becomes a whole different ball game. Especially in spinal cord injuries ascent of the lesion is not a rule, but catecholamines are highest, at least histochemically speaking, above the level of the lesion. This is not an observation which is new to our laboratory, it has been shown histochemically over and over again, and the fact that it cannot be reproduced biochemically only means that it is such a little amount and the variability of turnover is so much.

DR NosGeE. I think the question is very important. You cannot do any exact measuring levels without doing turnover studies, because turnover studies measure the dynamics of what is going on. We therefore, have started and finished actually our turnover studies using 2,6-ditrodiotyrosene which is of a very high specific activity and we have duplicated the work we have done previously just measuring the levels. We found that indeed norepinephrine levels do not change suddenly, they plateau when dopamine starts increasing. 